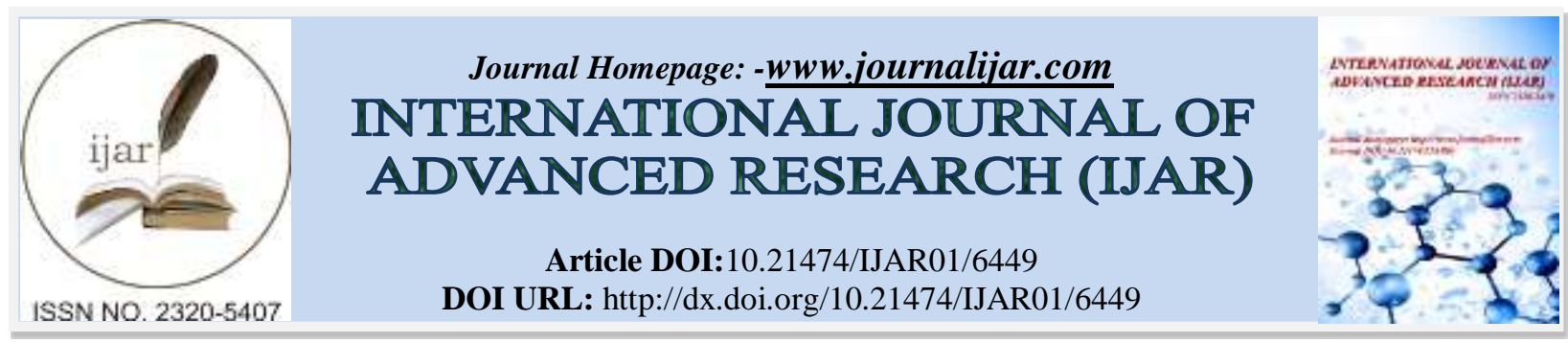

RESEARCH ARTICLE

\title{
DIGITAL ELEVATION MODELING OF SAINT MARTIN ISLAND, BANGLADESH: A METHOD BASED ON OPEN SOURCE GOOGLE EARTH DATA.
}

\author{
Faruk Hossain ${ }^{1}$, Salma Akter ${ }^{2}$ and Aktarul Ahshan ${ }^{3}$. \\ 1. Assistant Director, Geological Survey of Bangladesh. \\ 2. Deputy Director, Geological Survey of Bangladesh. \\ 3. Assistant Director, Geological Survey of Bangladesh.
}

Manuscript Info
Manuscript History
Received: 05 December 2017
Final Accepted: 07 January 2018
Published: February 2018
Keywords:-
DEM from Google Earth, Pearson
Correlation, Elevation profile, Accuracy
Assessment, ASTER, SRTM, High
Resolution.

\section{Abstract}

Many method or sources of data of the earth surfaces are well established for the digital elevation modeling. But all the traditional available high resolution data have not availability to easy access of public. Though the SRTM (90-meter, 30-meter) \& Global ASTER (30meter) DEM are now available for free of cost but resolution is not enough for large-scale small area.Many researcher different corner of the world try to established alternative way of Digital Elevation Modeling (DEM) through open sources data. Google earth is one of the most open sources tool of vast and diversifies free access data source. In this paper an attempt has taken to high resolution Digital Elevation Modeling of Saint martin Island, southern most territory of Bangladesh, based on open source Google earth data and a comparative assessment has done with SRTM 30, SRTM 90 and ASTER 30-meter resolution DEM. DEM was generated through extracted 58540 elevation points from Google earth of the study area. A comparative assessment through elevation profiling in same direction for all DEM and also a statistical correlation has performed. It was found that maximum elevation from DEM extracted from Google earth and SRTM (30-meter, 90-meter) DEM and ASTER 30meter DEM shows respectively 13, 13.92, 12.39, 18.40 meter and average elevation respectively as 5.053,5.259, 5.014, 9.523. Total sum, mean and median elevation of four different DEM shows that Google DEM strongly tie with SRTM 90 and SRTM 30, but deviation of ASTER 30-meter DEM with another DEM, as well as Google DEM are not negligible. Analysis of the result revealed that elevation extracted from Google Earth can be a good alternative source of elevation data, in some cases where as unavailability of enough data for small scale large area.

Copy Right, IJAR, 2018,. All rights reserved.

\section{Introduction:-}

Digital Elevation Model (DEM) usually represent the surface elevation of the earth. But fact of Resolution of DEM always not satisfy the demand of the study area. There are many sources of DEM are usually used to meet the several scientific purposes such as topographical analysis, hydrological modeling, slope stability analysis and so on. 
ASTER Global DEM or Advance Spaceborne Thermal Emission Radiometer Global Digital Elevation Model (DEM) and Shuttle Radar Thematic Mapper (SRTM) DEM are widely used global elevation data sources which are 30-meter, 90-meter and 90-meter resolution respectively. ASTER GDEM is a product of Ministry of Economy, Trade and Industry (METI) of Japan and National Aeronautics and Space Administration (NASA). ASTER Global DEM is now available for download free of cost in 1 Arc-Second or approximately 30 meters resolution for almost Global coverage. Coverage for digital elevation data of NASA's Shuttle Radar Topographic Mission (SRTM) has provided over $80 \%$ of the globe. Now this data is also distributed free of charge and available for download from the National Map Seamless Data Distribution System, or the United States Geological Survey website. The SRTM data is available as 1 Arc second and 3 Arc second (approximately 30 meters and 90-meter resolution) DEM. Though these elevation data are open access and free of cost but resolution of that DEM always not meet the site specific scientific and engineering applications.Due to increasing demand of high resolution DEM for specific applications and their unavailability also increase the alternative path of DEM generation.Many researcher different corner of the world try to established alternative way of Digital Elevation Modeling (DEM) through open sources Google Earth data. Google Earth provides high-resolution elevation data using the virtual globe system, which started in June 2005 and used Shuttle Radar Topography Mission (SRTM) data for its elevation baseline, Hoffmann and Winde, (2010). However, at some places the RMSE error of SRTM DEM is more than its specified accuracy of $\pm 16 \mathrm{~m}$, Sharma et al., (2010). Although Google Earth follow the SRTM elevation data, it has undertaken continuous refinement through consecutive addition of high resolution data from many sources as they become available. For these above facts it is need to carry out an accuracy assessment of Google Earth elevation data with other sources of DEM data. Rusli (2012), (2014) applied this method of extraction of Google elevation data for preparation of DEM from Google Earth and a comparative assessment were performed both in flat and hilly area and it had denoted that DEM extracted from Google Earth shows strong correlation with SRTM 90-meter DEM for flat area. They also found that ASTER 30-meter DEM shows strong correlation with Google extracted DEM for hilly area. Present study area also a flat area with an average elevation of 5-6 meter avobe mean sea level shows very strong correlation of Google extracted DEM with SRTM 30-meter and SRTM 90-meter DEM. Hirt et al. (2010) compared ASTER GDEM to SRTM and they noted that a large number of artefacts in GDEM, and found its vertical accuracy to be $\sim 15 \mathrm{~m}$ compared to $\sim 6 \mathrm{~m}$ for SRTM. SRTM which was obtained through SAR interferometry of C-band signals is available in 30 and $90 \mathrm{~m}$ spatial resolutions and an approximate vertical accuracy of $3.7 \mathrm{~m}$ (Syvitski et al., 2012). Relief also an important factor that has a strong effect on the vertical accuracy of SRTM DEM. In the low to medium-relief site, error is comparatively lower than high relief-terrain (Falorni.et.al., 2005). The vertical accuracy of SRTM is higher in areas with gentle slopes than on steep slopes; on low-lying floodplains SRTM has shown less than $2 \mathrm{~m}$ accuracy, Yan et al. (2015) and Jarihani et al. (2015). The present study focuses on the methodology of extraction of elevation data from Google Earth, due to preparation of comparatively high-resolution DEM from open sources data and a comparative assessment with others available DEM.

\section{Location Of The Study Area:-}

The study area Saint Martin Island lies in the north eastern part of the Bay of Bengal, it is about 13 kilometer from Cox bazar-Teknaf peninsular tip, 10 kilometer from Myanmar coast form Southern most territory and only coral Island of Bangladesh. Geographical position of the study area is $20^{\circ} 34^{\prime}-20^{\circ} 39^{\prime} \mathrm{N}$ and $90^{\circ} 18-92^{\circ} 21^{\prime} \mathrm{E}$ ( Fig. 1). It has an area of about 8 sq.km depending on tide, (Hassan \& Ahmad, 1996). The main Island can be divided into three part such as northern part (Uttar para), middle part and southern part (Dakhin para). Middle part of the island comparatively narrower than northern and southern part of the Island. Approximate total length of the main Island about 5 kilometer and maximum width of the northern part and southern part of the Island respectively as 1.66 and 0.97 kilometer The Island represent the westernmost extent of the Arakan Yoma uplift, Islam, (1980) and it is ringed by a boulder field in the intertidal zone prominent along the Southern and western shore of the Island, Khan, (1964), Islam,(1980). 


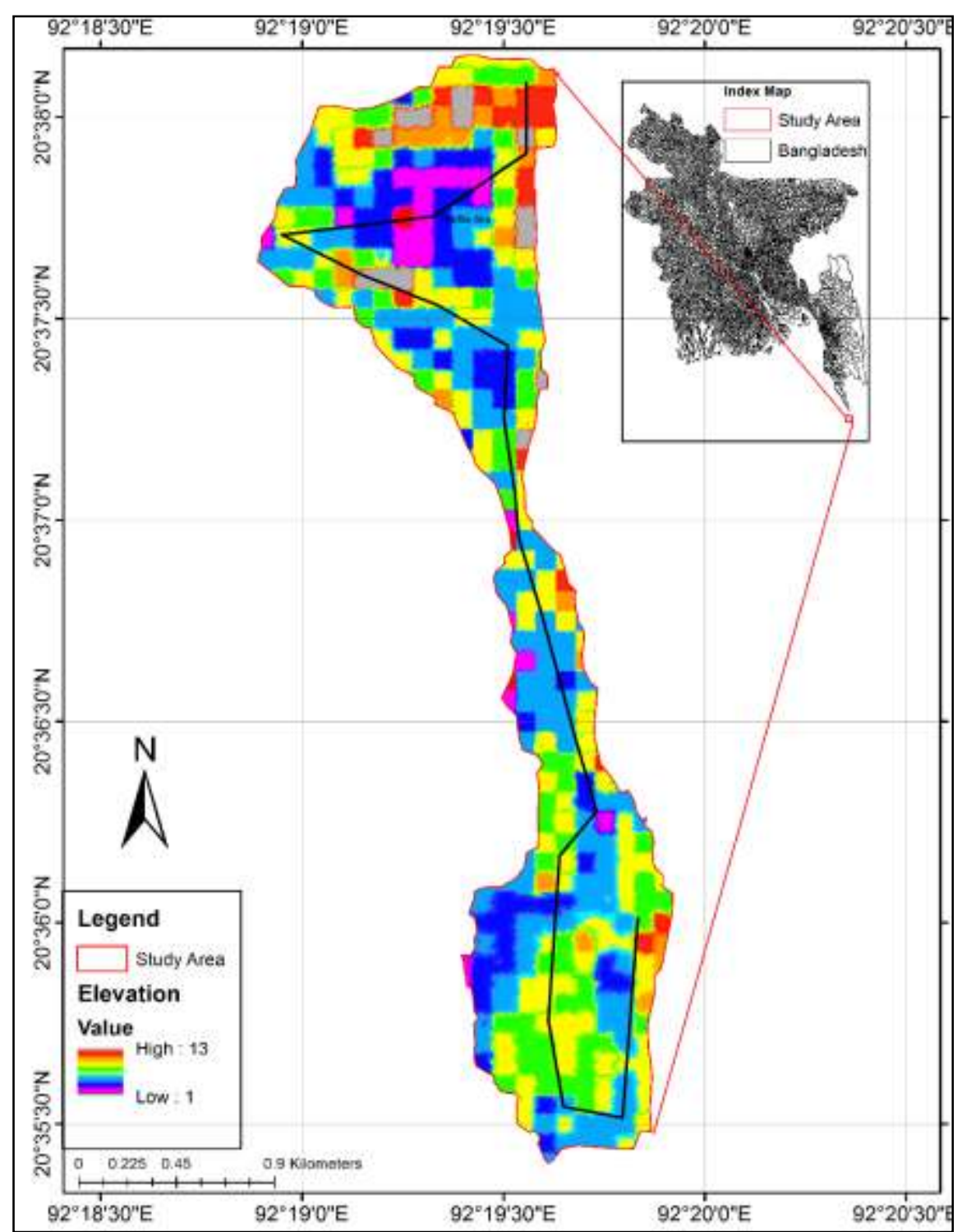

Figure 1:- Location map and DEM generated from Google Earth elevation data of the study area.

\section{Material and Methods: -}

Preparation of DEM from Google Earth: -

After selection of the study area Add Path tools of Google Earth Pro software are used to draw close spacing path over the study area and save as Kernel Markup Language (KML) file format. KML file are loaded in TCX converter with internet connection and converted as GPX file format by TCX converter software. Many GPS device and mapping software supports only a few kinds of files and had to deal with various file compatibility problem, but TCX converter is an open source software and have ability to import KML, GPX, FIT (Flexible Image Transport System), CSV and as well as ability to export KML, GPX, FIT, CSV files. In this research KML files are converted at GPX file by TCX converter and GPX file are converted as elevation shapefile by DNRGPS. DNRGPS is an easy to use software application that allow to manage, manipulate and save GPS information for use in GIS programs such as ArcMap. Elevation shapefile are loaded in ArcGIS software for further processing and preparation of DEM for the study area. Inverse Distance Weighted (IDW) interpolation method are used to interpolate total number of 58540 elevation data which are extracted from Google Earth for preparation of DEM. 


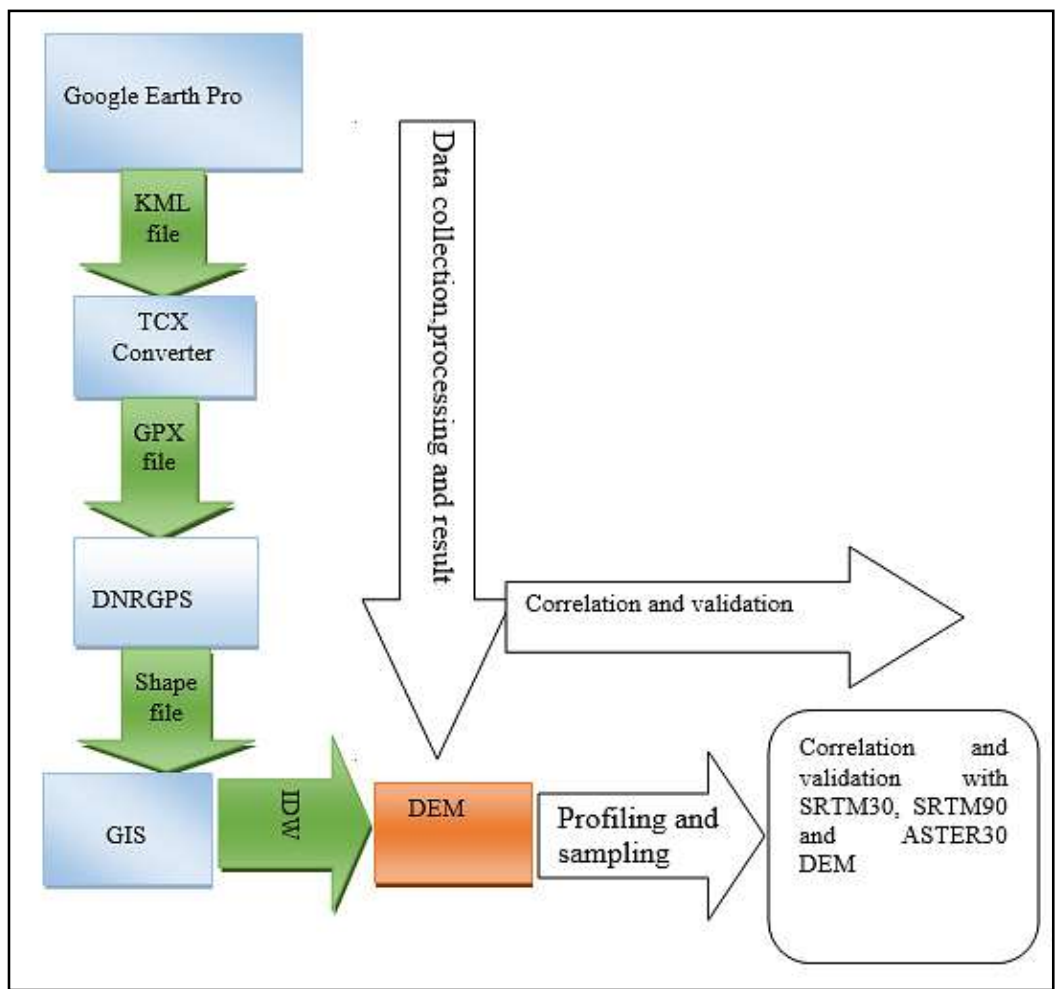

Figure 2:- Methodological flow chart

\section{DEM used for correlation: -}

30 meter and 90 meter resolutions Shuttle Radar Thematic Mapper (SRTM) DEM and 1 Arc-Second or 30 meters resolution scene of ASTGDEMV2-0N20E92 was downloaded from United States Geological Survey website by using Earth Explorer tool. All DEM were clipped for uniformity of the study area by using extract by mask tool of ArcGIS software.

\section{Profile plot: -}

1041 elevation point are extracted from same profile line (Fig. 3) of DEM from Google Earth, SRTM 30, SRTM 90 and ASTER 30 for comparative assessment and correlation of Google Earth elevation sample points and profile with others DEM. Global Mapper is another dynamic GIS software has a great ability to work with various file format and are used for same profile line along on DEM from Google Earth, SRTM 30, SRTM 90 and ASTER 30. Same Line of Sight are calculated for each of the DEM and exported as CSV file format and further processing in Microsoft Excel for ArcGIS environment. 


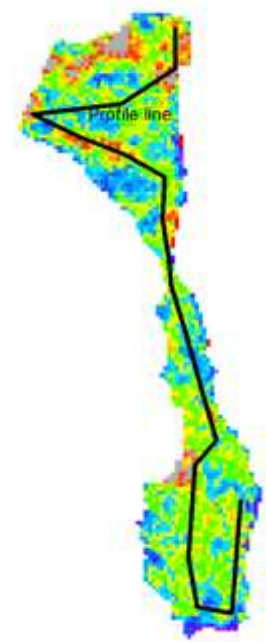

Profile Line for ASTER 30 DEM

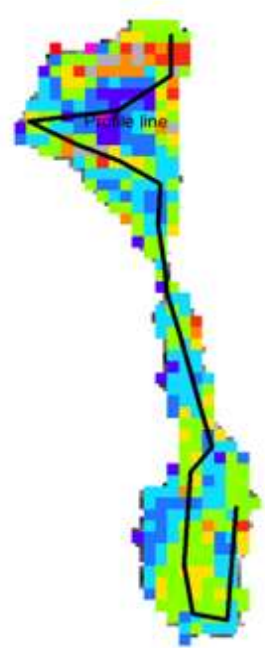

Profile Line for SRTM 90 DEM

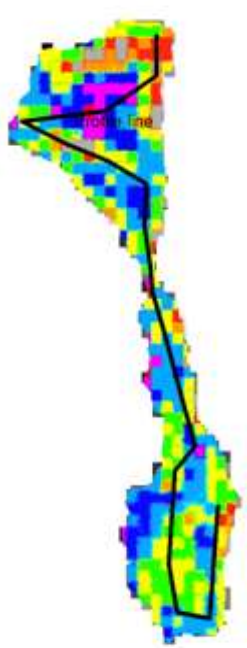

Profile Line for Google DEM

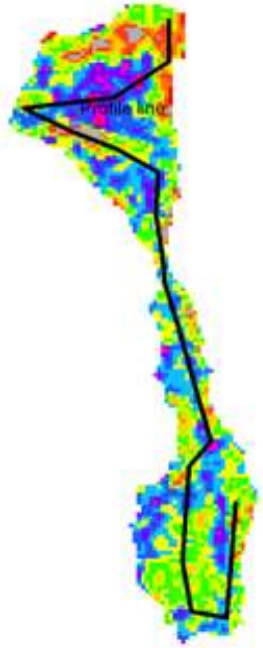

Profle Line for SRTM 30 DEM

Figure 3:- Profile line for Sampling of elevation data from different DEM (from left ASTER 30, SRTM 90, Google DEM and SRTM 30 DEM)

\section{Correlation: -}

Pearson's correlation:-

Finally, sample elevation points of different DEM with Google DEM are correlated by pairwise Statistical Regression analysis using JASP 0.8.5.1 an open source statistical analysis software. Pearson Regression correlation matrix test are performed for analysis of linear relationship of different elevation data. Pearson's correlation coefficient is a statistical measure of the strength of a linear relationship between paired data. In a sample Pearson's correlation denoted by the equation $-1 \leq \mathrm{r} \leq 1$, here $r$ is a Pearson's correlation coefficient and positive value of $r$ indicate positive correlation of pair data and negative value indicate negative correlation of data. Value of $r=0$ denote as no correlation. The magnitude of the correlation coefficient determines the strength of the correlation of data. According to Evans (1996) value of $r$ :

1. 0.00-0.19: "very weak"

2. 0.20-0.39: "weak"

3. 0.40-0.59: "moderate"

4. $0.60-0.79$ : "strong"

5. $0.80-1.0$ : "very strong

Table 1:- List of Software used for preparation, processing and analysis of elevation data

\begin{tabular}{|c|l|c|}
\hline No & Name of Software & Purpose/Output file/product \\
\hline 1 & Google Earth Pro & KML \\
\hline 2 & TCX converter & GPX, CSV \\
\hline 3 & DNRGPS & Elevation point shapefile \\
\hline 4 & ArcGIS & For profile line \\
\hline 5 & Global Mapper & Pearson Regression correlation \\
\hline 6 & JASP 0.8 .5 .1 & For profile line and graph \\
\hline 7 & Microsoft excel & \\
\hline
\end{tabular}

\section{Result and Discussion: -}

From statistical result it was found that minimum and maximum elevation extracted from google earth, SRTM 30, SRTM 90 and ASTER 30 are 1, 0.04900, 1.779 and 4.953 meter and maximum elevation 13, 13.92, 12.39, 18.40 meter respectively. Total sum, mean and median elevation of four different DEM shows that Google DEM strongly match with SRTM 90 and SRTM 30 but deviation of ASTER 30-meter DEM with another DEM as well as Google 
DEM are not negligible. (Table 2, Fig 5). Total sum and average elevation along profile elevation of 1041sample point for Google DEM, SRTM 30, SRTM 90, ASTER 30 are individually 5260.021,5475.135, 5215.474, 9912.988 and 5.0528, 5.2594, 5.0148, 9.522 meter (Table 2, Fig 5) and it was also found that average and total sum of elevation point for different DEM, especially Google DEM comparatively well match with SRTM 90 and SRTM 30 but a strong deviation observed over ASTER 30-meter DEM with another DEM elevation data. From Trendline and scatter plot graph (Fig 8) of different DEM value of $R^{2}$ for Google DEM, SRTM 30, SRTM 90 and ASTER 30 are $0.2197,0.2491,0.1948$ and 1 respectively and demonstrated that $R^{2}$ value for Google DEM, SRTM 30, SRTM 90 approximately same, except ASTER 30 DEM. According to Evans (1996) value of Pearson correlation coefficient $r$ for Google DEM Vs SRTM 30-meter and SRTM 90-meter respectively 0.905 and 0.881 for $95 \%$ lower and upper confidence level $0.893,0.915$ and $0.866,0.894$ respectively, which shows very strong correlation. But Value of $r$ for Google DEM Vs ASTER 30 for 95\% lower and upper confidence level $0.420,0.515$ shows 0.469 which are moderately associated (Table 3). In terms of value of $p$ from Pearson correlation for pair data of Google DEM Vs SRTM30, SRTM 90 and ASTER GDEM 30 shows a statistically significant correlation, where p value for pair data $<0.001$ (Table 3). From Table 2. Value of skewness for Google DEM, SRTM 30, SRTM 90 and ASTER 30 separately demonstrated as 1.216, 1.100, 1.134 and 1.072. Skewness generally measure the symmetry of data distribution and normal distribution have a Skewness of zero, $H o \& Y u$ (2015). Positive skewness indicate data skewed to the right and negative value of skewness also indicate lefted skewness of data. Value of Kurtosis for Google DEM, SRTM 30, SRTM 90 and ASTER 30 correspondingly demonstrated as 2.086, 1.623, 2.097 and 1.413. All of them DEM kurtosis data showed a thin tailed (Fig. 11) and though the same spatial resolution of SRTM 30 and ASTER 30, showed a comparative kutosis difference 0.210, but a minor variation observed between Google DEM and SRTM 90 which have only 0.011 . Kurtosis $(K)$ a statistical term used to measure the tail end of data distribution where as data are skinny tail or flat tail. The standard normal distribution has a kurtosis $(K)$ of three, value of $K<3$ indicate platykurtic (less peakedness, weaker tails, heavy shoulder), $k>3$ is leptokurtic (more peakedness, heavy tails, weak shoulders), $H o \& Y u$ (2015). Therefore, if observed data have a kurtosis greater than three, it is said to have heavy tails when compared to the normal distribution. If the data have a kurtosis less than three, it is said to have thin tails. So the data have a kurtosis less than three and have a similarity of thin tails. According to the American Heritage Science Dictionary, standard deviation used in statistics as a measure of the dispersion or variation in a distribution, which equal to the square root of the arithmetic mean of the squares of the deviations from the arithmetic mean. Standard deviation (Sd) of four DEM from Table 2. Indicate that dispersion or variation of data of SRTM 30 and ASTER 30 have more compare to Google and SRTM 90 DEM and which observed respectively as 2.462, 2.392, 2.002 and 1.798. Sd difference between Google vs SRTM 30, ASTER 30 and SRTM 90 observed respectively as $0.460,0.390$ and \pm 0.204 , indicated a less variability of Google and SRTM 90-meter DEM of the study area, comparative to others DEM. Another Comparative analysis of $25^{\text {th }}$ percentile or $1^{\text {st }}$ quarter data, $50^{\text {th }}$ percentile or median data and $75^{\text {th }}$ percentile or $3^{\text {rd }}$ quarter data of different DEM (Table 2., Fig 11) observed a quarterly variation or differences of data. Value of $25^{\text {th }}$ percentile data of Google DEM, SRTM 30, SRTM 90 and ASTER 30 observed respectively as 4.000, 3.692, 3.949 and 7.895. differences of observed value of that DEM with Google DEM respectively as $0.308,0.051,-3.895$. Value of $50^{\text {th }}$ percentile data of Google DEM, SRTM 30, SRTM 90 and ASTER 30 observed respectively as 4.697, 4.789, 4.746 and 9.028. differences of observed value of that DEM with Google DEM respectively as $-0.092,-0.049,-4.331 .3^{\text {rd }}$ quartile Value of Google DEM, SRTM 30, SRTM 90 and ASTER 30 observed respectively as 6.000, 6.329, 5.899 and 10.91. differences of observed value of that DEM with Google DEM respectively as $-0.329,1.899,-4.91$. From above percentile data analysis it was found that differences of Google DEM with SRTM 30 and SRTM 90 have a positive value in 1st quartile, negative differences in 2nd quartile and in 3rd quartile it shows respectively as negative and positive differences.But ASTER 30 in all quartile with others DEM shows negative differences and negativity increases from 1st quartile to 3rd quartile. It was also revealed that differences of Google DEM with SRTM 90, SRTM 30 was very lower compare to ASTER 30 in all quartile of the data. 


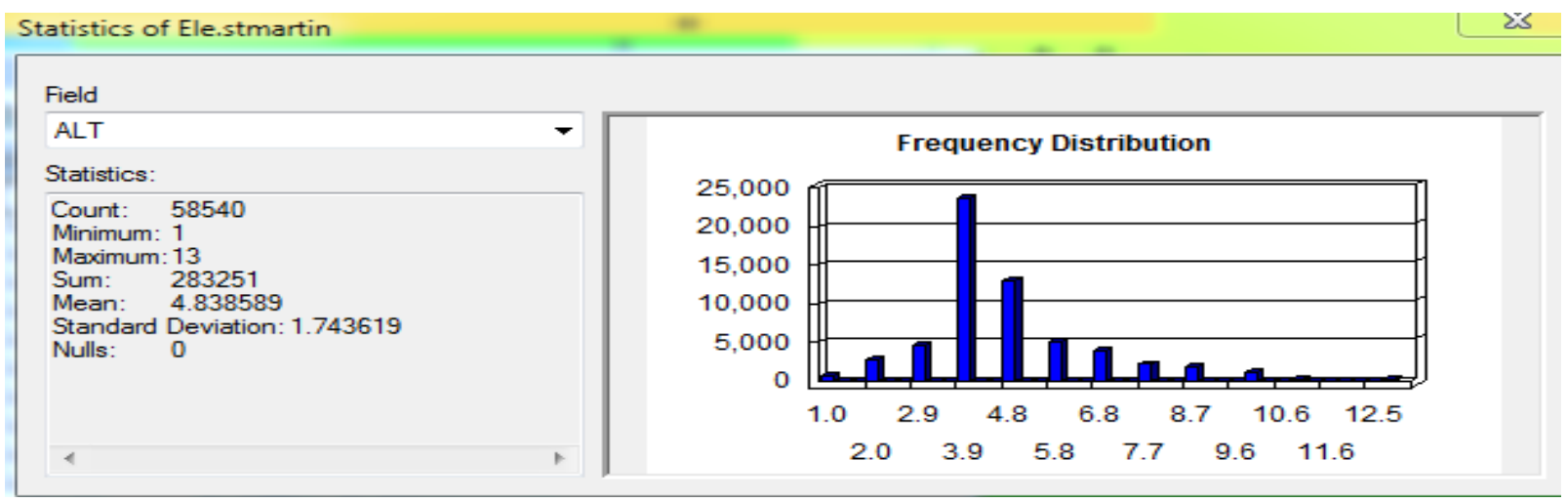

Figure 4:- Statistics of total elevation point for DEM preparation from Google Earth data.

From comparative profile line graph of Google DEM with SRTM 30, SRTM 90 and ASTER 30, it was also found that overlapping of Google DEM profile strongly fitted with SRTM 30 and SRTM 90 but differ with Aster 30-meter DEM (Fig. 5, Fig. 6, Fig. 7, Fig. 8 and Fig. 9).

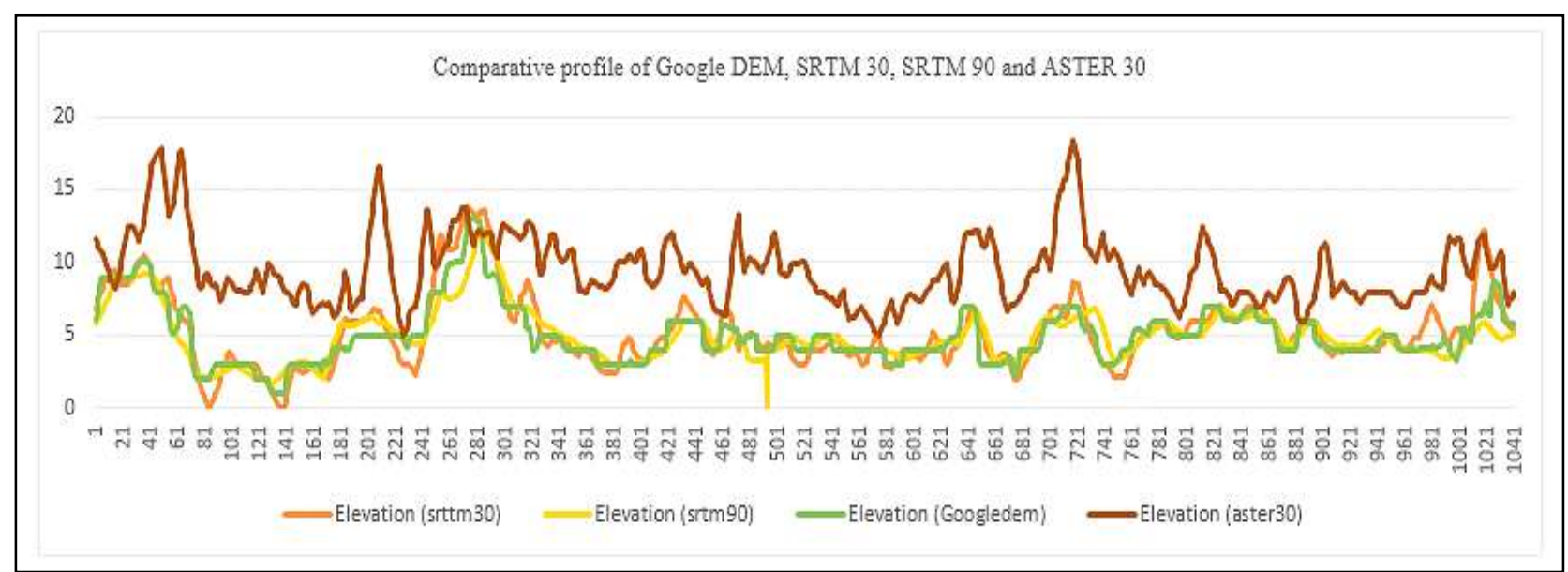

Figure 5:- comparative profile line graph of Google DEM, SRTM 30, SRTM 90 and ASTER 30 shows strong profile match of Google DEM with SRTM 30, SRTM 90 but strong deviation shows with ASTER 30-meter DEM.

Table 2:- Descriptive Statistics of Sample elevation profile data for different DEM

\begin{tabular}{|c|c|c|c|c|c|}
\hline & $\begin{array}{c}\text { Elevation } \\
\text { (Googledem) }\end{array}$ & Elevation (srtm30) & $\begin{array}{l}\text { Eleva } \\
\text { (srtn }\end{array}$ & $\begin{array}{l}\text { Eleva } \\
\text { (aste }\end{array}$ & $\begin{array}{l}\text { tion } \\
\text { 30) }\end{array}$ \\
\hline Valid & 1041 & 1041 & 1041 & 1041 & \\
\hline Missing & 0 & 0 & 0 & 0 & \\
\hline Mean & 5.053 & 5.259 & 5.014 & 9.523 & \\
\hline Median & 4.697 & 4.789 & 4.746 & 9.028 & \\
\hline $\begin{array}{l}\text { Std. } \\
\text { Deviation }\end{array}$ & 2.002 & 2.462 & 1.798 & 2.392 & \\
\hline Skewness & 1.216 & 1.100 & 1.134 & 1.072 & \\
\hline $\begin{array}{l}\text { Std. Error of } \\
\text { Skewness }\end{array}$ & 0.07581 & 0.07581 & 0.07581 & 0.07581 & \\
\hline Kurtosis & 2.086 & 1.623 & 2.097 & 1.413 & \\
\hline $\begin{array}{l}\text { Std. Error of } \\
\text { Kurtosis }\end{array}$ & 0.1515 & 0.1515 & 0.1515 & 0.1515 & \\
\hline Minimum & 1.000 & 0.04900 & 1.779 & 4.953 & \\
\hline Maximum & 13.00 & 13.92 & 12.39 & 18.40 & \\
\hline Sum & 5260 & 5475 & 5219 & 9913 & \\
\hline 25th & 4.000 & 3.692 & 3.949 & 7.895 & \\
\hline
\end{tabular}




\begin{tabular}{|l|l|l|l|l|l|l|l|l|}
\hline percentile & & & & & & & \\
\hline $\begin{array}{l}\text { 50th } \\
\text { percentile }\end{array}$ & 4.697 & 4.789 & & 4.746 & & 9.028 & \\
\hline $\begin{array}{l}\text { 75th } \\
\text { percentile }\end{array}$ & 6.000 & 6.329 & 5.899 & & 10.91 & \\
\hline
\end{tabular}

Table 3:- Pearson Correlations (Google DEM Vs SRTM 30, SRTM 90 and ASTER 30-meter DEM)

\begin{tabular}{|c|c|c|c|c|c|c|c|}
\hline & & & \multicolumn{2}{|c|}{ Pearson's $\mathrm{r}$} & $\mathrm{p}$ & $\begin{array}{c}\text { Lower } 95 \% \\
\text { CI }\end{array}$ & Upper $95 \%$ CI \\
\hline $\begin{array}{l}\text { Elevation } \\
\text { (Google-dem) }\end{array}$ & - & $\begin{array}{l}\text { Elevation } \\
\text { (srtm30) }\end{array}$ & 0.905 & $* * *$ & $<.001$ & 0.893 & 0.915 \\
\hline $\begin{array}{l}\text { Elevation } \\
\text { (Google-dem) }\end{array}$ & - & $\begin{array}{l}\text { Elevation } \\
(\text { srtm90) }\end{array}$ & 0.881 & $* * *$ & $<.001$ & 0.866 & 0.894 \\
\hline $\begin{array}{l}\text { Elevation } \\
\text { (Google-dem) }\end{array}$ & - & $\begin{array}{l}\text { Elevation } \\
\text { (aster30) }\end{array}$ & 0.469 & $* * *$ & $<.001$ & 0.420 & 0.515 \\
\hline
\end{tabular}

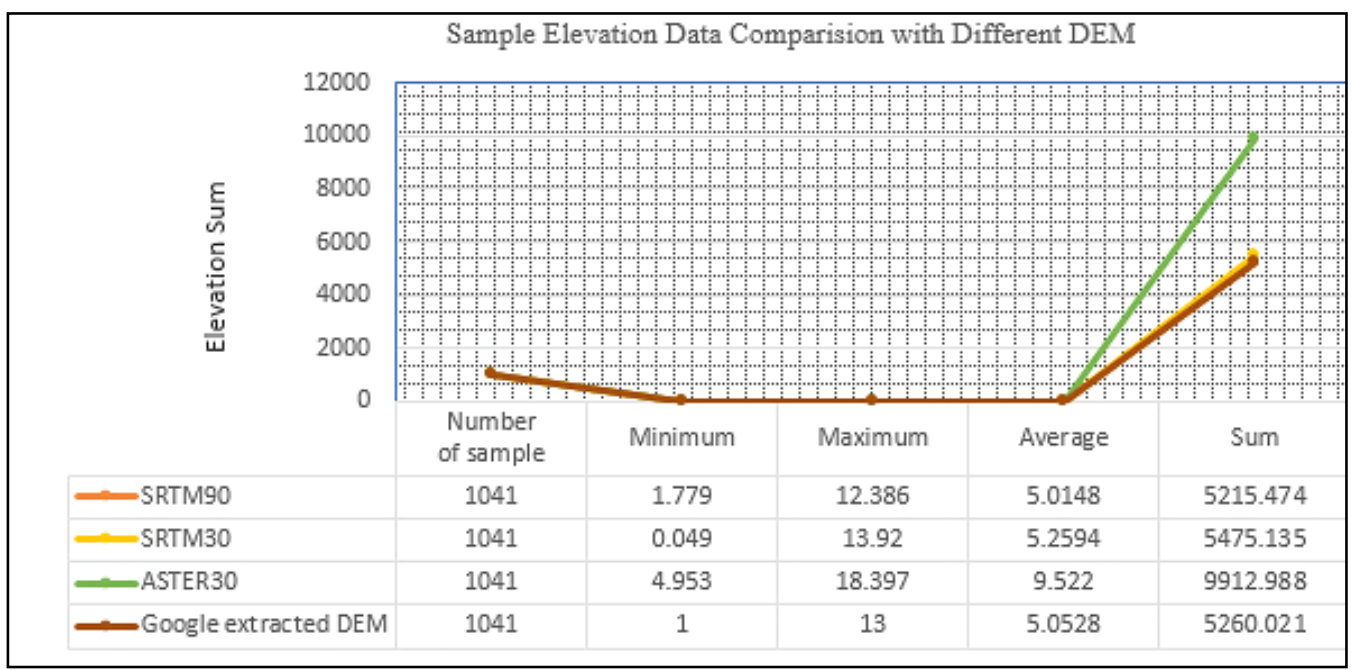

Figure 6:- Analysis of 1041 elevation sample point from same location for SRTM90, SRTM30, ASTER 30 and Google extracted DEM. Google extracted DEM highly match with SRTM90 and SRTM30 except ASTER 30, which are not fully match with Google extracted DEM.

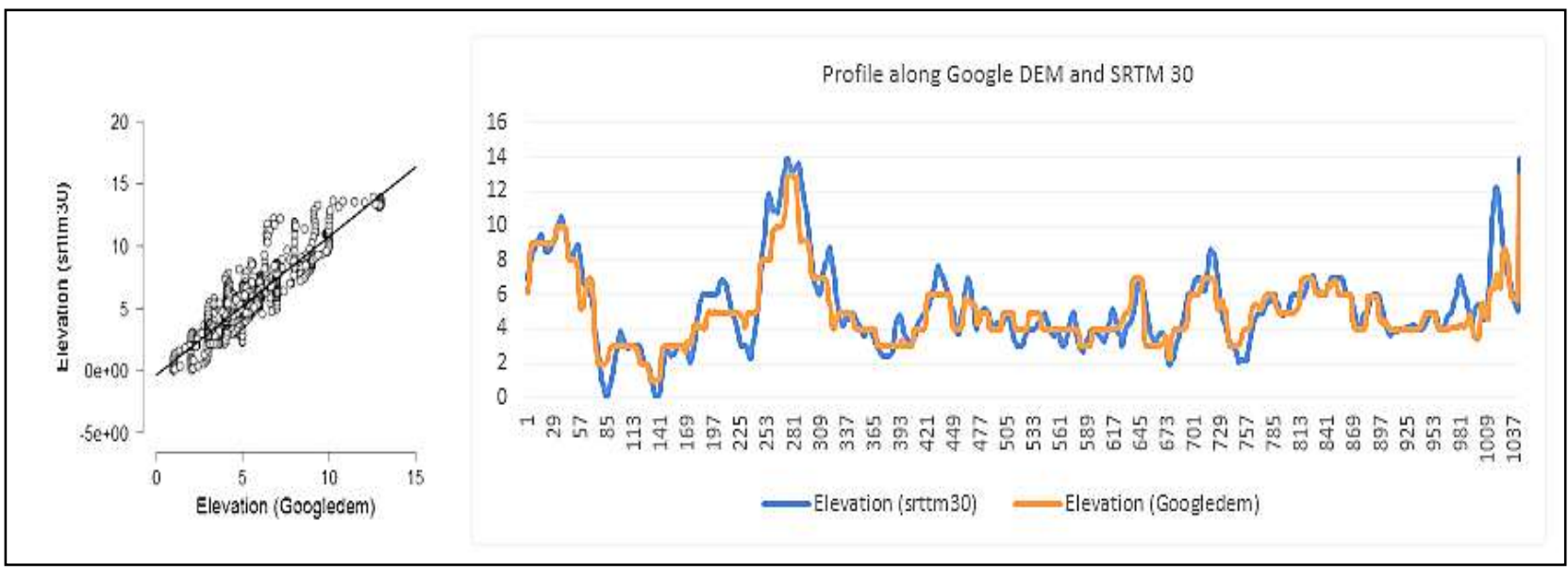

Figure 7:- Correlation and comparative profile line of Google DEM and SRTM 30 shows very strong correlation and profile match between Google DEM Vs SRTM 30-meter DEM. 


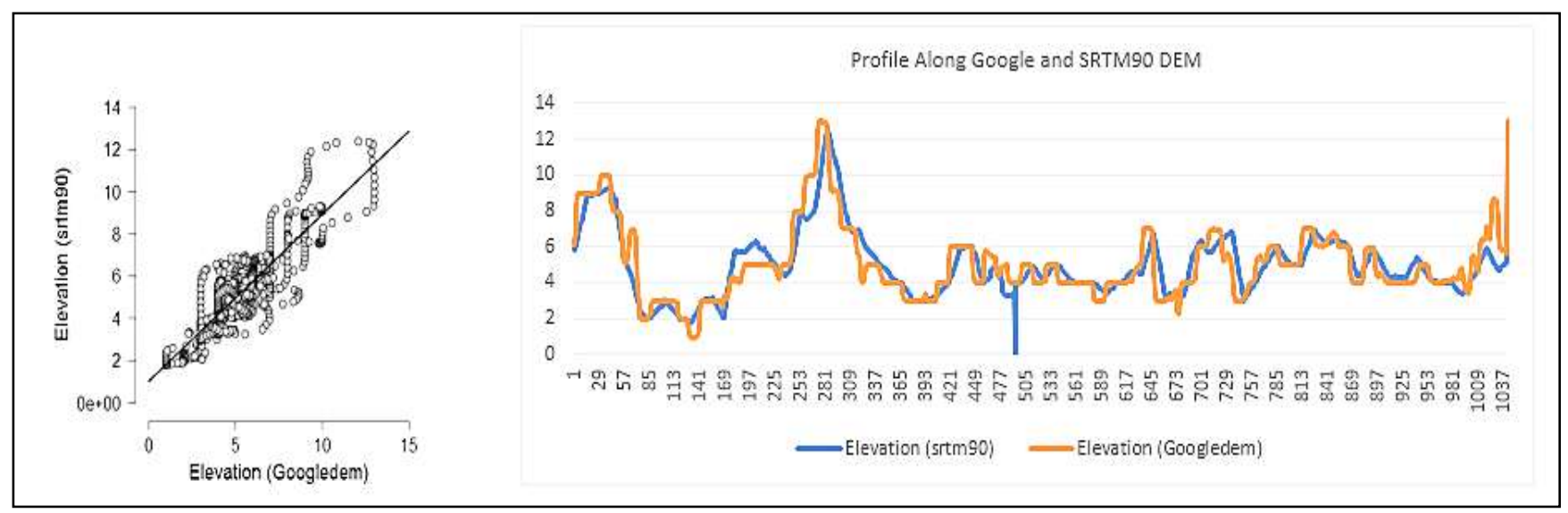

Figure 8:- Correlation and comparative profile line of Google DEM and SRTM 90 shows very strong correlation and profile match between Google DEM Vs SRTM 90-meter DEM.

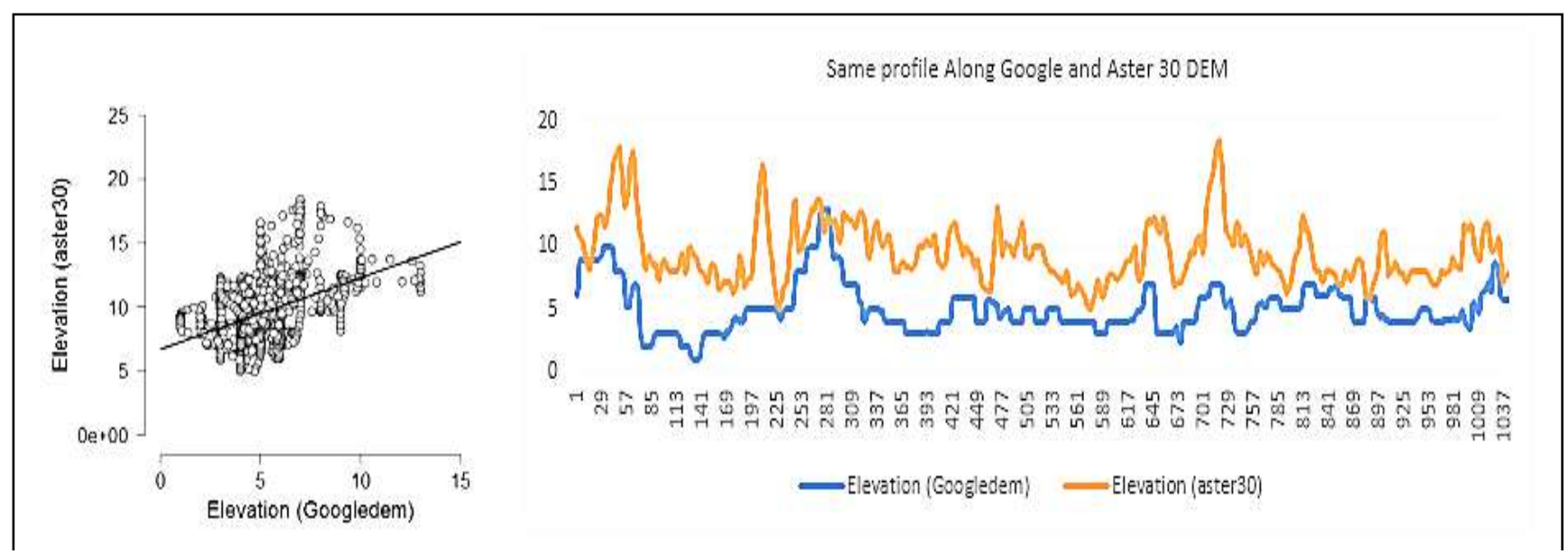

Figure 9:- Correlation and comparative profile line of Google DEM and ASTER 30 shows moderate correlation and profile match between Google DEM Vs ASTER 30-meter DEM. 


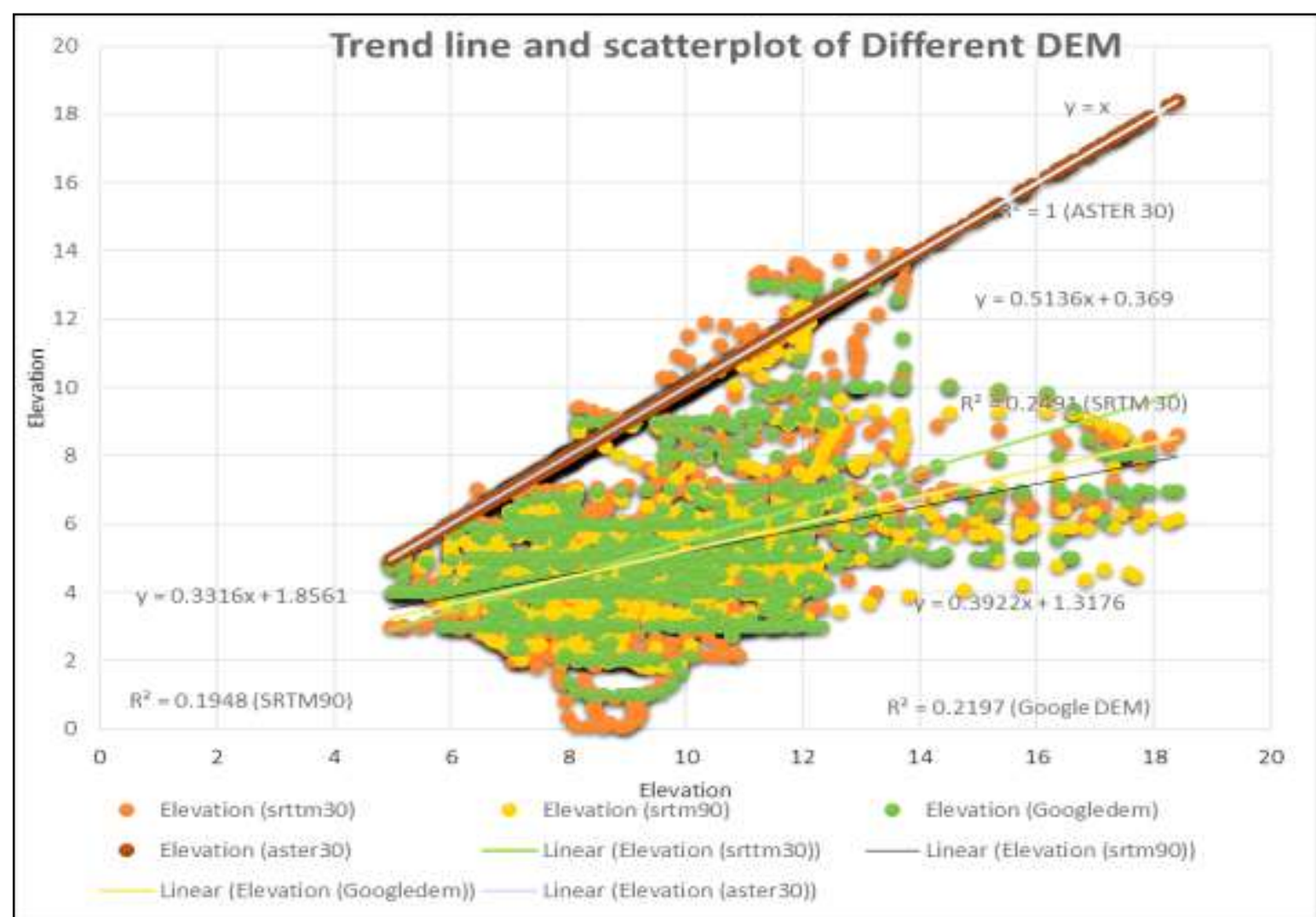

Figure 10:- Trendline and scatter plot of different DEM shows strong correlation of SRTM 30, SRTM 90 with Google DEM.

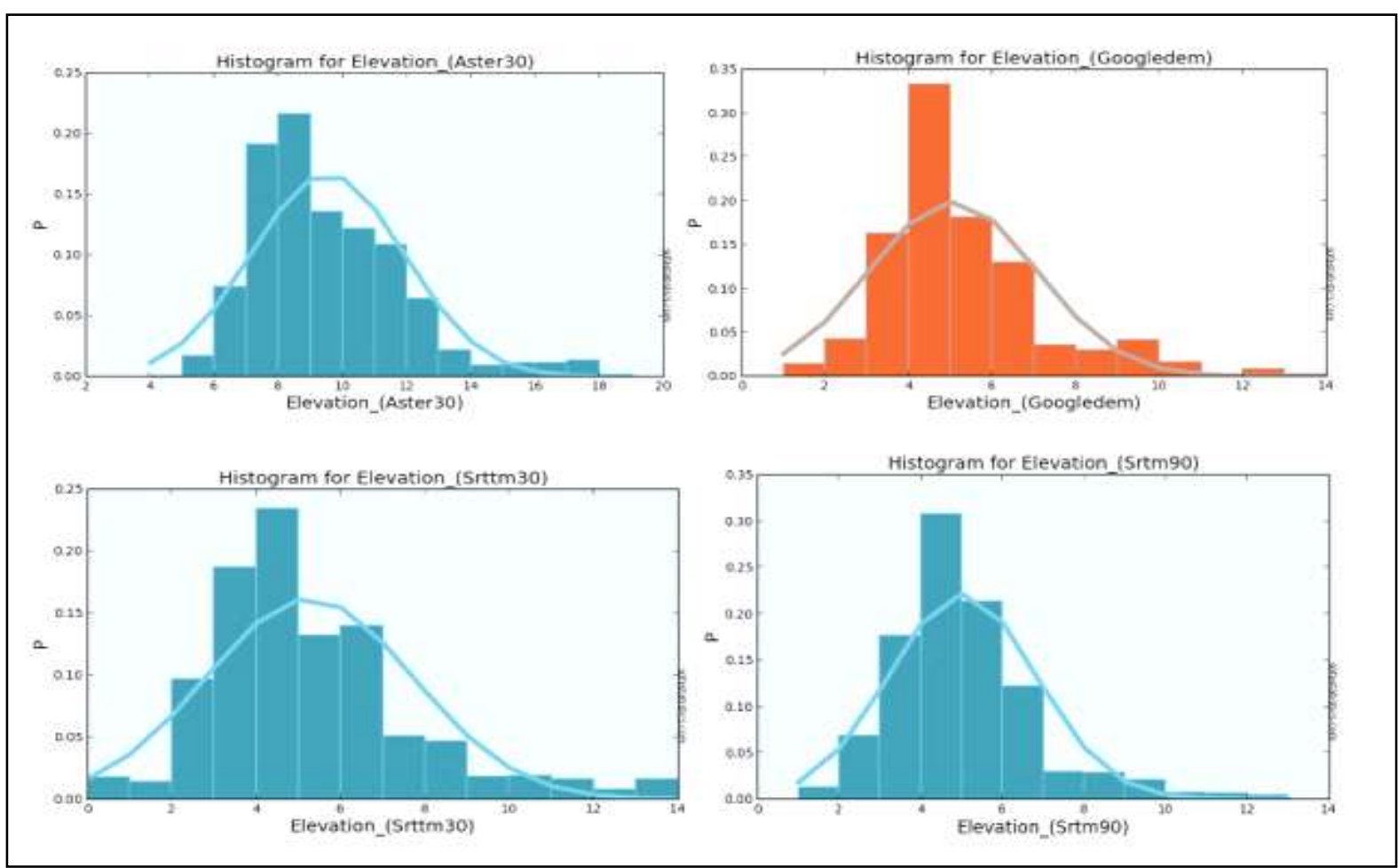

Figure 11:- Histogram of sample elevation points of different DEM. 


\section{Conclusion:-}

From result and comparative analysis of different DEM of the study area, it was significantly revealed that DEM extracted from Google earth have showed a satisfactory result over others DEM, especially SRTM 90 shows very strong similarity and SRTM 30 also shows a strong similarity in all aspect of the study. DEM extracted from Google Earth can be a good alternative of SRTM 90 and SRTM 30 for flat area, because the study was conducted only on a flat area. But it also be noted that ASTER 30-meter resolution of DEM strongly differ not only DEM extracted from Google Earth, but also with SRTM 90 and SRTM 30 for the same location elevation points of the study area.

\section{References:-}

1. Anderson, J.S., and Barnes, L.G. (2000): A fossil Miocene whale from the Tipam Sandstone, St. Martin's Island, Bangladesh. - Oryctos, 3: 79-84.

2. Evans, J. D. (1996). Straightforward statistics for the behavioral sciences. Pacific Grove, CA: Brooks/Cole Publishing.

3. Falorni, G., V. Teles, E. R. Vivoni, R. L. Bras, and K. S. Amaratunga (2005), Analysis and characterization of the vertical accuracy of digital elevation models from the Shuttle Radar Topography Mission, J. Geophys. Res., 110, F02005, doi:10.1029/2003JF000113

4. Hirt, C., Filmer, M. S., and Featherstone, W. E. (2010). Comparison and validation of the recent freely available ASTER-GDEM ver1, SRTM ver4. 1 and GEODATA DEM-9S ver3 digital elevation models over Australia. Australian Journal of Earth Sciences, 57(3), 337-347.

5. Ho, o, A. D., \& Yu, C. C. (2015). Descriptive statistics for modern test score distributions: Skewness, kurtosis, discreteness, and ceiling effects. Educational and Psychological Measurement.

6. Hoffmann, E., \& Winde, F. (2010). Generating high-resolution digital elevation models for wetland research using Google EarthTM imagery: an example from South Africa. Water SA, 36(1), 53-68.

7. ISLAM, M.A. (1980). Neogene shatigraphy and sedimentation of the St. Martin's Island, Bangladesh. Joumal of the University of Shffield Geological Society, $7: 269-275$.

8. Jarihani, A. A., Callow, J. N., McVicar, T. R., Van Niel, T. G., \& Larsen, J. R. (2015). Satellite-derived Digital Elevation Model (DEM) selection, preparation and correction for hydrodynamic modelling in large, lowgradient and data-sparse catchments. Journal of Hydrology, 524, 489-506.

9. KHAN, F.H. (1964). Geology of St. Martin's Island- Record of the Geological Survey of Pakistan, 10 (2-B): 1I2.

10. Rusli, N., \& Majid, M. R. (2012). Digital Elevation Model (DEM) Extraction from Google Earth: a Study in Sungai Muar Watershed. AGSE 2012-FOSS4G-SEA, 24.

11. Rusli, N., Majid, M. R., \& Din, A. H. M. (2014). Google Earth's derived digital elevation model: A comparative assessment with Aster and SRTM data. In IOP Conference Series: Earth and Environmental Science (Vol. 18, No. 1, p. 012065). IOP Publishing

12. Sharma, A., Tiwari, K.N. and Bhadoria, P.B.S. (2010). Vertical Accuracy of Digital Elevation Model from Shuttle Radar Topographic Mission - A Case Study, Geocarto International, Vol 25, No 4, pp 257-267.

13. standard deviation. (n.d.). The American Heritage ${ }^{\circledR}$ Science Dictionary. Retrieved February 8, 2018 from Dictionary.com website http://www.dictionary.com/browse/standard-deviation

14. Syvitski, J. P., Overeem, I., Brakenridge, G. R., \& Hannon, M. (2012). Floods, floodplains, delta plains-a satellite imaging approach. Sedimentary Geology, 267, 1-14.

15. Qumrul, M., Kazi, H., and Ahmed, M. (1996). Hydrochemistry of Ground Water in the St. Martin's Island, Bangladesh. JOURNAL-BANGLADESH ACADEMY OF SCIENCES, 20, 145-154.

16. Yan, K., Di Baldassarre, G., Solomatine, D. P., \& Schumann, G. J. P. (2015). A review of low-cost space-borne data for flood modelling: topography, flood extent and water level. Hydrological Processes, 29(15), 3368-3387. 